\section{Construcción de comunidad: un 28 de julio en la ciudad de Puerto Madryn}

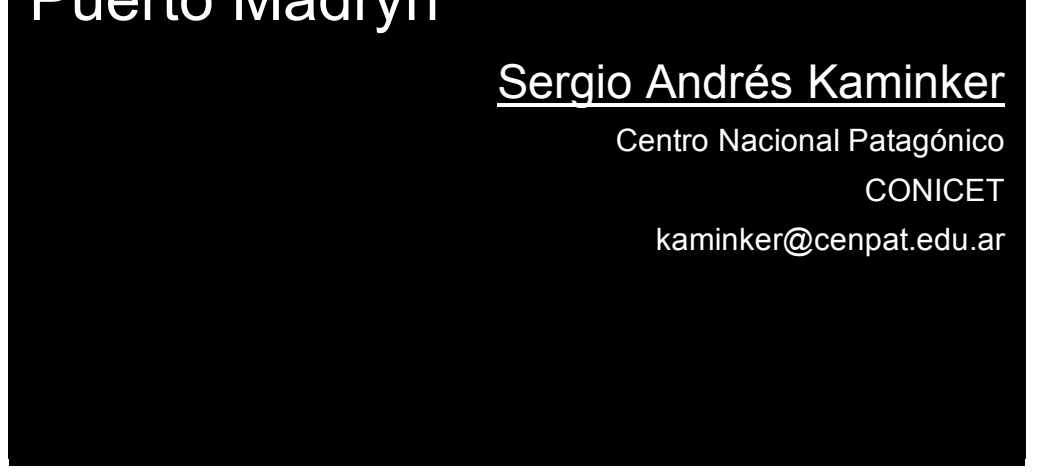

\section{Papeles del CEIC \\ ISSN: 1695-6494}

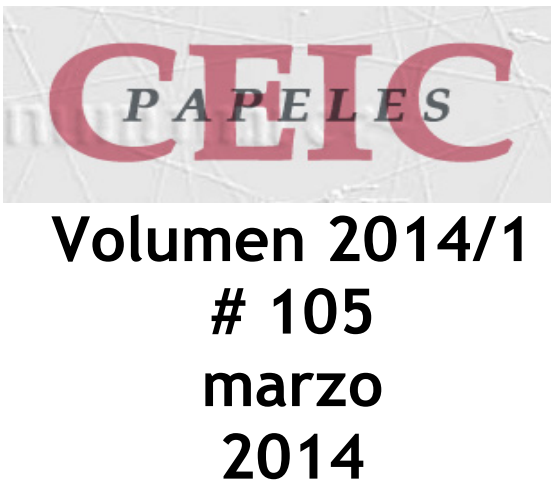

Resumen

Construcción de comunidad: un 28 de julio en la ciudad de Puerto Madryn
Abstract

The construction of community: 28 July in the city of Puerto Madryn

En este artículo se indagará la construcción de comunidad en el festejo oficial de la Fundación de la This paper will explore the construction of community on ciudad de Puerto Madryn, Provincia de Chubut, July 28th in the official celebration of the Founding of Argentina. A través de la relectura de algunas the city of Puerto Madryn, Chubut Province, Argentina. herramientas conceptuales de la sociología clásica, Through the rereading of some conceptual tools of propias de Weber y Durkheim, se buscará problematizar classical sociology, from Weber and Durkheim, we seek el evento del 28 de julio cuando se conmemora el to set out the event that commemorates the landing of desembarco galés en Chubut, poniendo en cuestión si Welsh in Chubut, considering if it's an expression of este es una manifestación del multiculturalismo o bien multiculturalism or an opening of the identification core una apertura del núcleo de identificación local de la of the societal community of the city in the terms of comunidad societal de la ciudad, en términos de Parsons.

Parsons.

\section{Palabras clave}

Comunidad, multiculturalismo, identidades, Patagonia
Key words

Community, multiculturalism, identities, Patagonia

\title{
Índice
}

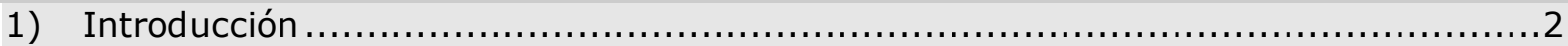

2) Distintos sentidos de comunidad: entre la sociología clásica y Parsons ....................

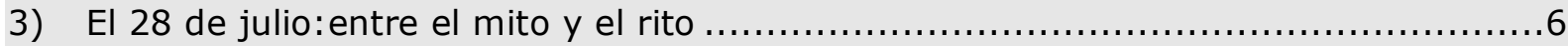

4) Multiculturalismo o la expansión de la comunidad societal ............................. 15

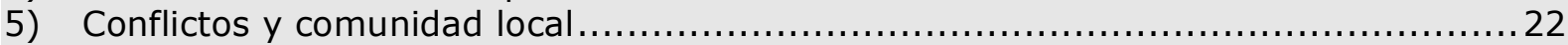

6) Conclusiones: entre la identidad local y el conflicto social ............................ 27

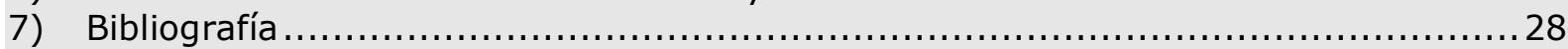




\title{
1) INTRODUCCIÓN
}

\begin{abstract}
"Valoramos con espíritu fraterno a los pueblos originarios preexistentes, a las familias pioneras galesas y a los/as inmigrantes que permitieron y permiten la construcción de una comunidad pluricultural”. (Fragmento del Preámbulo de la Carta Orgánica Municipal de la Ciudad de Puerto Madryn, Septiembre de 2010)
\end{abstract}

En el presente trabajo indagaremos sobre la construcción de comunidad en el festejo de la fundación de la ciudad de Puerto Madryn del 28 de julio de 2011, como parte de nuestra investigación que busca comprender las formas que adquiere la segregación en dicha ciudad de la Patagonia argentina ${ }^{1}$. Tomando en consideración algunos autores de la sociología clásica, la idea es hacer una lectura exploratoria, a través de una etnografía de los significados en pugna, las negociaciones y los conflictos envueltos en un acto que en términos de Durkheim (1996: 642) podríamos interpretar como un rito de actualización de un momento de "efervescencia creadora".

La reflexión resulta interesante por el peso simbólico del acto del festejo del 28 de julio en la ciudad de Puerto Madryn (y en la provincia de Chubut) y por haber adquirido cada vez mayor atención no sólo de parte de las autoridades, sino de varios de los colectivos involucrados en el mismo. La imagen que se produce y negocia en éste, adquiere peso y cierta performatividad en los imaginarios locales con efectos en términos de jerarquías y/o niveles de subalternización de determinados sujetos en la dinámica social local. En particular, el evento resulta muy significativo en una ciudad en constante expansión demográfica y urbana desde la década de 1970' para comprender las formas que adquieren los conflictos a nivel local y

\footnotetext{
${ }^{1}$ El artículo se enmarca en la investigación doctoral "Migraciones, urbanización y segregación residencial en Puerto Madryn, Chubut (1991-2010) iniciada en 2011 en el Centro Nacional Patagónico, dependiente de CONICET, Argentina. 
cómo son pensados y tratados tanto por las autoridades como por los propios habitantes.

En primer lugar, explicitamos los distintos sentidos de comunidad que nos interesa desarrollar teniendo en cuenta que los conceptos de comunización en Weber, de efervescencia colectiva y comunidad moral en Durkheim y comunidad societal en Parsons resultan herramientas de una potencialidad vigente para el análisis actual de las formas en que se tramitan las identidades colectivas. Tras este punto de partida, iniciamos el recorrido por el mito y el rito que significa el 28 de julio en la construcción del imaginario social madrynense, para luego vislumbrar cómo opera el mismo en una tensión entre el reconocimiento de las diferencias típicamente multicultural y una expansión de esa comunidad societal. Finalmente, abordamos conflictos emergentes en el evento, intentando desentrañar jerarquías y niveles de subalternización de los distintos colectivos locales para llegar a formular preguntas más generales sobre la relación entre reconocimiento y redistribución en las formas en las cuales se co-construyen las identidades colectivas.

\section{2) Distintos SENTIDOS de COMUNIDAD: ENTRE LA SOCIOLOGÍA CLÁSICA Y PARSONS}

Los autores clásicos de la sociología han problematizado la polaridad conceptual "comunidad-sociedad" como parte de sus análisis de un cambio epocal en su contexto histórico de emergencia. En el programa de estos teóricos clásicos, nos encontramos con tres objetivos o sentidos de la comunidad: como parte de un pasado, como forma de analizar las relaciones en el presente o bien con un sentido programático (de Marinis, 2005). Aquí nos interesa recuperar para el presente análisis los sentidos que Durkheim y Weber le dieron a la idea/concepto "comunidad", porque aún gozan de cierta vigencia para comprender fenómenos sociales. 
En primer lugar, nos interesa retomar el concepto de "comunización" en Weber, cuando refiere a éste como "una relación social cuando y en la medida en que la actitud en la acción social (...) se inspira en el sentimiento subjetivo (afectivo o tradicional) de los partícipes de constituir un todo" (1984: 33). Como bien esgrime de Marinis (2010a: 28), el concepto de comunización, o proceso de comunión, conlleva la idea de una relación, o proceso, dinámica. Es más, el refinamiento de la argumentación weberiana nos permite ir más allá, dado que diferencia entre una relación de comunización "abierta al exterior cuando (...) no se encuentra negada por los ordenamientos que rigen esa relación", o cerrada "al exterior cuando y en la medida en que aquella participación resulte excluida, limitada o sometida a condiciones por el sentido de la acción o por los ordenamientos que la rigen" (1984: 35). Weber entiende así que esta relación es "una posibilidad siempre abierta, como una eventualidad, como una posibilidad de 'recalentamiento' de los lazos sociales aún en (y quizás debido a) los contextos abiertos por una racionalización y un desencantamiento crecientes" (de Marinis, 2010a: 20). Más allá de estos planteamientos, como afirma Torterola, estas formas de relación "son susceptibles de conjugar en la práctica elementos racionales según fines y/o valores, y afectivos" (2010: 15), escapando a una simplificación en el análisis.

En segundo lugar, nos pareció pertinente trabajar con algunas nociones de la obra de Durkheim. Cabe recordar, como afirma Ramos Torre, que el "problema central de la sociología de Durkheim era el de la reconstrucción moral de la sociedad moderna". En consecuencia, la indagación de la comunidad en este autor es sobre la "comunidad moral" (2010: 384). Ahora bien, el gran aporte de Durkheim que nos interesa es su resignificación de lo comunitario en la efervescencia o la fusión colectiva en clave política (Grondona, 2010):

"No puede haber ninguna sociedad que no sienta la necesidad de mantener y revitalizar, a intervalos regulares, los sentimientos 
colectivos y las ideas colectivas que le dan unidad y la individualizan. Pero esa reconstrucción moral sólo puede obtenerse mediante reuniones, asambleas y congregaciones en las que los individuos, en estrecha proximidad, reafirmen en común sus sentimientos comunes" (Durkheim, 1996: 641).

Para Durkheim, entonces, "la comunidad ritual (...) se presenta siempre en el núcleo fundacional de toda sociedad" (Ramos Torre, 2010: 402). He aquí el lugar que cobra la efervescencia colectiva, como efervescencia creadora, construyendo mitos, momentos acotados que se van renovando a través de los ritos, sean estos religiosos o laicos, como forma de explicar lo propiamente colectivo, qué nos mantiene unidos (Ribes, 2010). Durkheim afirma así que "esa realidad que las mitologías se han representado de tantas formas distintas, pero que es la causa objetiva, universal y eterna de las sensaciones sui generis que constituyen la experiencia religiosa, es la sociedad" (1996: 629). En este sentido es que nos interesa interpretar el festejo del 28 de julio, no como esa "comunidad sagrada fundante" a la cual no se puede tener acceso por el paso del tiempo que la devora (Ramos Torre, 2010: 400), sino como un rito donde los sentidos aparecen reactualizados en un festejo, en una dinámica procesual donde el conflicto está presente (Ribes, 2010).

Por último, retomamos un desarrollo conceptual de Parsons, por su potencialidad para pensar los procesos de ampliación de la ciudadanía, en particular la noción de comunidad societal, por su capacidad para pensar a ese núcleo identitario que hace a la integración del sistema social en su teoría. Ese núcleo estructural de la sociedad que piensa como su subsistema integrativo, conteniendo valores y normas, pero que fundamentalmente hace a un concepto de membresía (de Marinis, 2010c: 65). Aún a costas de la ambigüedad del concepto, que bien explicita Alexander (2005), mantiene cierta capacidad analítica para escenarios de transformaciones sociales 
graduales $^{2}$. Éste nos permite cuestionarnos acerca de la forma en que podemos pensar la identidad local de la ciudad y los procesos de abstracción e inclusión y acceso a la "comunidad pluricultural madrynense" de la Carta Magna Municipal.

Es entonces desde estos tres desarrollos sociológicos escogidos que buscaremos analizar y poner en cuestión los sentidos que aparecieron en el festejo del 28 de julio, en 2011.

\title{
3) EL 28 DE JULIO: ENTRE EL MITO Y EL RITO
}

\begin{abstract}
"Una sociedad no puede crearse ni recrearse sin crear, al mismo tiempo, el ideal. Esa creación no es para ella una especie de acto gratuito, mediante el cual se complementaría una vez formada; es el acto gracias al que se forma y se reconstituye periódicamente" (Durkheim, 1996: 635).
\end{abstract}

El 28 de julio de cada año se conmemora en Chubut la llegada de los colonos galeses a territorio provincial. "El desembarco", como se lo conoce, es una marca, un hito fundacional de la "gesta" de los colonos galeses, pero también un mito central de la identidad provincial de Chubut en general y de Puerto Madryn en particular. No es casual entonces que ese día sea uno de los dos feriados provinciales ${ }^{3}$, junto al "Día del Petróleo" ${ }^{4}$. Fue un 28 de julio de 1865 cuando llegaron en el barco "Mimosa" un primer grupo de colonos

\footnotetext{
${ }^{2}$ Resulta particularmente sugerente la tesis de Sadrinas según la cual el "conflicto" sería uno de los factores determinantes de la integración social en la obra de Parsons. Sin embargo, "diversidad y pluralidad de intereses e identificaciones" (2012: 156) no necesariamente es conflicto en Parsons, sino que justamente la posibilidad de mayores universalizaciones en las definiciones de membresía de un colectivo evitarían conflictos. Si bien compartimos con Sadrinas que la preocupación de Parsons por el orden social no implica que haya sido un teórico conservador ni una visión simplista e ingenua de lo social, tampoco creemos que haya sus desarrollos una teoría social del conflicto como parecería sostener este autor.

${ }^{3}$ Según la ley provincial $\mathrm{N}^{\circ} 2258$, sancionada en 1984.

${ }^{4}$ Se conmemora el 13 de diciembre de cada año. Un trabajo aparte merecería el lugar del petróleo en la historia de la provincia del Chubut, en especial en el espacio físico e idiosincrasia de la ciudad de Comodoro Rivadavia. Algunas cuestiones interesantes sobre la historia de Comodoro Rivadavia se pueden revisar en la compilación de Baeza, Crespo y Carrizo (2007).
} 
que se instalaría en un espacio que venían preparando otros que se adelantaron a su llegada, alrededor de un mes antes, previo beneplácito del Estado nacional y paso por Carmen de Patagones ${ }^{5}$. Estos llegarían a un lugar del Golfo Nuevo conocido como Punta Cuevas, en el extremo sur de la ciudad de Puerto Madryn, donde hoy hay un "Museo del Desembarco" y existen unas placas que recuerdan el desembarco y a unos pocos metros distancia se erige una estatua de un Indio Tehuelche. Es en las inmediaciones de este sitio, hoy declarado "Parque Histórico Punta Cuevas", donde "se celebra cada año, el pacífico encuentro entre colonos y nativos junto a la piedra consagrada por la comunidad mapuche-tehuelche", según establece la ordenanza №6966, del 11 de diciembre de $2008^{6}$.

Fue, entonces, el 28 de julio de 2011 el evento que a continuación se relata, siendo que éste tiene varios significados, no sólo el desembarco de los galeses en este territorio, sino el aniversario $146^{\circ}$ de la fundación de la ciudad de Puerto Madryn y el encuentro entre los que llegaron y los que ya vivían allí. En los sentidos explicitados en el apartado anterior, nos interesa leer este festejo como un ritual, una forma de actualización o reactualización de cierto sentido comunitario local, en el cual la identidad local no sólo se festeja, sino que se performa de diversas maneras. En consecuencia, se establecen membresías, no escapando a conflictos y silencios, sino sancionando un relato específico en el cual diversas comunidades participan en una relación de comunización en el sentido otorgado por Weber ${ }^{7}$.

\footnotetext{
${ }^{5}$ Para mayor información se pueden revisar las actas de los cinco foros internacionales sobre los galeses en la Patagonia realizados desde el año 2002. Cabe agregar que los foros juegan un papel importantísimo en la construcción y reconstrucción del lugar de los galeses en la Patagonia.

${ }^{6}$ En esta ordenanza se busca formalizar un organismo que tenga en cuenta que "es necesario preservar los recursos históricos de nuestra ciudad como medio para fortalecer la identidad local" y propicie "acciones de cultura general e interés comunitario en pos del fortalecimiento de la identidad regional y del turismo cultural". Boletín Oficial $N^{\circ} 420$, Municipalidad de Puerto Madryn.

${ }^{7}$ Cabe advertir no es de nuestro interés inmiscuirnos en la discusión acerca del momento fundacional, el 28 de julio de 1865 y la historia de la colonización galesa, la cual se suele caracterizar como "pacífica", en contraposición a la expoliación, el despojo o el conflicto posteriores del Estado nacional argentino en construcción, lo que dejamos a la discusión más 
Nos interesa reflexionar sobre este rito como una forma de analizar la integración y la segregación, dado que la entendemos no sólo en términos de sectores sociales emplazados en diferentes espacios físicos ${ }^{8}$, sino también en espacios sociales. Así, buscamos mostrar cómo en un evento determinado el lugar de los actores e instituciones es central, no sólo por su carácter oficial, sino por su acceso o no al relato social local, y lo que ello puede habilitar en términos de acceso a derechos.

Lejos de abonar cierto pintoresquismo enamorado por festejos y tradiciones, las cuales muchas veces coadyuvan a una folklorización de eventos, el objetivo es comprender qué sentidos podemos vislumbrar a través de los momentos de condensación que este ritual implica, teniendo en cuenta jerarquizaciones, contrastes, silencios, marcas e imágenes que más allá de ser cuestiones mentadas o no, podemos intentar analizar 9 .

Ingresando en el desarrollo de la jornada, el evento comenzó alrededor las 7:50 de la mañana, dado que el primer acto fue una rogativa ${ }^{10}$ de la

historiográfica. Sobre la misma, resulta interesante las dimensiones introducidas por Ariel Williams (2007) sobre la historiografía de la colonización galesa y su proyecto de lectura de esta. A su vez, si interesa esta cuestión cabe revisar las críticas introducidas por Vezub (2005) a la visión del comercio entre galeses y tehuelches como forma complementaria y pacífica de relacionarse. Por último, Lopez y Gatica problematizan "los motivos de la inclusión en el relato memorialista de éste 'gesto fundacional', poniendo en cuestión el lugar de igualdad histórica en el cual se los ubica a tehuelches y galeses (2008). Cabe agregar que, por la falta de agua la falta de agua la gran mayoría de la colonia galesa se terminó instalando en la zona del Valle Inferior del Río Chubut (Jones, 2004) y que el trazado original de la ciudad lo realizó la empresa ferroviaria recién en 1906 (Sanabra, 2004).

${ }^{8}$ Esta dimensión la hemos comenzado a desarrollar en otro trabajo, Kaminker (2011).

${ }^{9}$ En vez de analizar los festejos realizados por cada colectividad que pueden pensarse como formas de expresión de cultura popular específicos de un grupo, en esta ocasión, prestamos atención a un evento "oficial", como es la conmemoración del 28 de julio en Puerto Madryn. Sin embargo, no resulta llamativo que se haya actualizado y transformado en los últimos años, apareciendo negociaciones y conflictos materializados en el festejo, en sus discursos e imágenes. En particular, entendemos que nos encontramos con un rito, no como mera forma de reproducción e internalización de paradigmas políticos particulares, sino con una dimensión cognitiva y performativa en la cual se pone en juego la integración social, pero también la emergencia de intereses y conflictos (Lukes, 1975).

${ }^{10}$ La "rogativa", oración o ruego, colectivo que suelen hacer las comunidades mapuches es un rito que suele ser conocido con otros nombres (camaruco, nguillatun), pero que tiene varias funciones, desde "actualizar la relación con los antepasados (...) mantener y fortalecer las relaciones sociales con otros miembros de la comunidad" (...) u otras comunidades hasta la "propiciación de la realidad deseada" (Golluscio, 2006: 41). 
comunidad mapuche-tehuelche Pu Fotum $\mathrm{Mapu}^{11}$ cuando salió el sol. Ésta, que según se explicó ese día, comenzó a realizarse hace unos diez años aproximadamente, se considera parte de la agenda oficial del día ${ }^{12}$.

Sin embargo, no tenía presencia de funcionario alguno de la municipalidad o de la provincia. Además de hombres, mujeres, niños, niñas y adolescentes de la comunidad en cuestión, entre los cuales sumaban cerca de 25 personas, había miembros de otras comunidades mapuches-tehuelches de otras partes de la provincia y algunos de la misma ciudad. A su vez, participó de la rogativa un hombre que pertenecía a la Asociación Cultural Galesa que luego sería parte del acto central. Luego, éramos unas 40 personas que observábamos el ritual sin participar del mismo. Es importante tener en cuenta que uno debe ser invitado a participar. Se puede observar pero por fuera del semicírculo formado para el rito. En el centro estaba la fogata, el lonko ${ }^{13}$ de la comunidad mapuche-tehuelche Pu Fotum Mapu, Ángel Ñanco, comenzó a hablar sobre la rogativa, "un rito sagrado", sobre la significación de hacerla el día de la fundación de la ciudad, del "encuentro de dos culturas", por la recuperación cultural que ellos desean hacer, de su historia, de sus antepasados que eran quienes conocían sus tierras, pero siempre como parte de la ciudad de Puerto Madryn. Dedicó la rogativa a un anciano que había fallecido recientemente y que había sido una de las fuentes de conocimiento más importantes para su comunidad $^{14}$, a las personas de la comunidad y otras comunidades que los acompañaban en ese

\footnotetext{
11 "Pu Fotum Mapu" significa "los hijos de la tierra" en mapudungun.

${ }^{12}$ Cabe agregar que el Municipio generó una agenda de 9 días de actividades alrededor de los festejos del $146^{\circ}$ aniversario de la ciudad, pero que la centralidad de los festejos son el mismo 28, en el cual se llevan adelante los actos centrales que también son los más asistidos por ser este un día no laborable en la provincia.

${ }^{13}$ El "lonko" es el jefe o autoridad máxima de una comunidad mapuche.

14 En este sentido, es interesante saber que las comunidades mapuche-tehuelches de la ciudad se han (re)constituido sobre todo en los últimos diez años, por lo que necesitaron ayuda de otras comunidades que mantenían los ritos para poder comenzar sus propias prácticas.
} 
día (si bien no dejó de marcar ciertas diferencias con otras comunidades de la misma ciudad).

Después, cerca del mediodía, comenzó el "acto central". Este fue la ritualización del "desembarco" y del "encuentro de dos culturas" en sí. La actualización del mito que funciona como una forma de comunión de la "comunidad local", de la "identidad local", como veremos a continuación. En primer lugar, se hizo la recreación del desembarco, con la ayuda de la Prefectura Naval Argentina, lo cual según explicitaron se comenzó a hacer hace unos 10 años también. En unos botes venían unos descendientes de colonos galeses vestidos en forma tradicional. Portaban dos banderas celestes y blancas con un dragón rojo en el medio, símbolo de los galeses en Argentina. Iban acompañados por personal de prefectura y fueron ayudados por buzos para montar cuatro caballos provistos por una organización tradicionalista de la región para ir desde el barco hasta la playa. Cabe mencionar que había un relato en altavoz de quién oficio de locutor que durante el acto, quien hablaba de "los intrépidos colonos galeses" o de "pioneros que han escrito la historia de la ciudad". Había cobertura de medios y varias familias con niños y niñas que se acercaban a la playa para que estos vieran la representación. Además de las banderas, uno de los que desembarcó tenía un rifle en mano y otro una pala. Se sacaron fotos y ordenadamente, se acercaron al "encuentro de dos culturas", es decir al encuentro con la comunidad mapuche-tehuelche. Quien presidía el encuentro por parte de los galeses era el único no-indígena que había participado de la rogativa de la mañana dentro del semicírculo y quien lo hacía por parte de la comunidad mapuche-tehuelche era el lonko de la comunidad. A sus costados estaban sus mujeres y detrás sus hijos y otras familias. Por parte de los galeses, hacían parte del acto unas 6 o 7, en cambio, junto al lonko estaba casi toda su comunidad, alrededor de 25 personas. Se dieron un abrazo y un beso, y hubo un intercambio de pan y carne. 
Comenzó a sonar música mapuche. Había algunas personas emocionadas por el encuentro. Luego, el coro municipal cantó una canción galesa. A continuación, se cantó el himno nacional argentino y el himno nacional galés. Se nombraron a todos los presentes, autoridades nacionales, provinciales, municipales, vecinos, miembros de distintas organizaciones. Formados a los costados del escenario, había representantes de escuelas, representantes de organizaciones de la colectividad galesa, del Centro de Residentes de bolivianos Wuyñay, una banda de música de la policía y miembros de comunidades mapuche-tehuelche.

A diferencia de la rogativa, en este acto había mucha presencia de familias con niños y niñas, pero también de autoridades oficiales de diverso nivel y jurisdicción, desde la policía provincial y Prefectura, hasta el vicegobernador, el intendente saliente de Puerto Madryn, el intendente electo, diputados provinciales y concejales, una diputada nacional y otras autoridades diversas y hasta enfrentadas públicamente en la arena política ${ }^{15}$.

En este punto, podemos afirmar que la (re)presentación del acto fundacional, del desembarco y del encuentro entre galeses y nativos, funciona más que como un mero festejo simbólico, como una suerte de textualidad de los primeros colonos reflejada en la necesidad de fijar cómo se dieron los "hechos", en palabras de Williams en su análisis de la historiografía de la colonización galesa, en una "cosificación de la historia y de su relato" que

15 Fue de público conocimiento en Argentina las denuncias de fraude, elecciones complementarias y enfrentamiento político por las elecciones para gobernador en la provincia de Chubut entre el intendente saliente de la ciudad de Puerto Madryn y actual diputado de la nación, Carlos Tomás Eliceche, quien respondía al gobierno nacional presidido por Cristina Fernández de Kirchner, y el actual gobernador Martín Buzzi, quien respondía al anterior gobernador Mario Das Neves. Esto derivó en un acercamiento del actual gobernador Martín Buzzi al gobierno nacional, a pesar de haber sido candidato a gobernador opositor al mismo. Lo mismo sucedió en el plano local, donde el candidato que respondía al gobierno nacional, el anterior vice intendente Carlos Lazaro perdió, por pocos votos y con elección complementaria incluida, la intendencia a manos de Carlos Sastre, actual intendente de la ciudad, quien respondía al anterior gobernador provincial Mario Das Neves. Un relato de ese día final de elecciones se puede ver en la nota publicada en Página 12 el 30 de mayo de 2011 titulada "Y 69 días más tarde se eligió gobernador". Link: http://www.pagina12.com.ar/diario/elpais/1169123-2011-05-30.html 
opera como una "fetichización de los hechos" (2007: 12) centrales de la colonización.

Por ello, tiene sentido plantear que el relato, la narración que surge del acto y de sus discursos, cobra una centralidad local que tiene consecuencias más allá de este, en las representaciones colectivas de los diversos grupos sociales locales, no sólo como expresión de cierta opinión o visión de la historia, sino también en sus efectos a nivel social, en el tratamiento hacia el "otro" o en ciertas posibilidades de acceso a recursos estatales locales.

Al terminar las menciones e introducciones, comenzaron los discursos. Durante todo el acto hubo una suerte de ficción de paz entre las distintas autoridades. No hubo ningún roce vinculado a lo político, aún los discursos de funcionarios como el vicegobernador y el intendente saliente, que tuvieron cierta dosis de proselitismo, no fueron de enfrentamiento. Fue como un momento de suspensión de los conflictos políticos, aunque no para algunas de las personas presentes que, como veremos más adelante, fueron la única presencia disonante del acto.

En los discursos se buscó dar cuenta de una idea del valor de ese momento mítico, el de la llegada de los galeses, de la convivencia pacífica con el tehuelche, momento fundacional del cual los protagonistas actuales son continuadores y tras el cual yace la fuente de identidad local de la ciudad de Puerto Madryn, anclada también en los valores morales de estos primeros habitantes, colonos y tehuelches, que más allá de la pertenencia a estos colectivos primarios, deben ser compartidos para ser parte de la "comunidad madrynense".

En este sentido, el lonko de la comunidad expresaba que los galeses se encontrarían con "los habitantes originarios de la Patagonia, es decir, a los tehuelches o tehuelchos", "un pueblo netamente pacífico que manejaban valores fundamentales como el de la convivencia en paz, la solidaridad, el 
CEIC

respeto por el prójimo". Siguió en la caracterización de estos señalando que trataban con amor a sus familias, que eran amables. Que eran grandes cazadores y conocedores del curso del agua y de "los recursos que la tierra les brindaba". Agregó que "todas estas características y todos los conocimientos fue lo que el pueblo tehuelche brindó al galés", que no se fijaron en las diferencias que "no tuvieron en cuenta el color de la piel, ni siquiera el hablar idiomas diferentes obstaculizó la relación que se estaba generando entre estos pueblos logrando el afianzamiento definitivo de los galeses en Patagonia"16.

A su vez, la representante de la Asociación cultural galesa, Nelcis Jones, explicitaba que estaban recordando "la llegada de un grupo de galeses lleno de ilusiones que movidos por un ideal eligieron esta tierra", que "llegaron convencidos de que querían ser ellos mismos, que no podían perder la lengua de sus padres, sus tradiciones, que no podían claudicar luego de tantos años de trabajo". A su vez exaltaba que se habían establecido en una marcha "hacia una convivencia marcada por el intercambio, encuentro y el entendimiento"17, realizando un paralelismo entre galeses y tehuelches al señalar que también ellos eran un pueblo sometido en términos económicos, cultuales y lingüísticos ante una potencia, que "tal vez esto los unió más a los pobladores de aquí", quienes "los recibieron, acompañaron y sostuvieron en las penurias de los primeros tiempos".

Es en ellos, "los continuadores" o "descendientes" de los primeros colonos y de aquellos nativos que estaban en el primer encuentro, en quienes se encarna ese acto fundacional del "encuentro de las dos culturas" y el "desembarco" previo. Se busca recuperar, así, esa "efervescencia colectiva" que hace a la comunión entre estos pueblos y demanda reponer en lo local ese sentido de comunidad político. Es a través de esta relación de

${ }_{17}^{16}$ Cabe aclarar que las cursivas en los discursos son propias.

${ }^{17}$ Las cursivas son propias.

Sergio Andrés Kaminker 
comunización entre estos colectivos, pero de la cual también participan las autoridades municipales y provinciales que se busca dar cuenta, a su vez, de esa "comunidad local" como "comunidad moral" en la cual subyacen ciertos valores comunes, propios de esos "pioneros" y "tehuelches" que los recibieron. Los discursos de unos y otros son una muestra de esto.

Quien fuera intendente de Puerto Madryn hasta el 10 de diciembre de 2011, Eliceche, dijo en el acto que la historia de la ciudad mostraba que "quienes nos precedieron, fueron y son un verdadero ejemplo de tenacidad, perseverancia, tolerancia, fidelidad a un ideal de pluralidad" y los caracterizó como "personas capaces de sostener sus ideales y defenderlos" e "idealistas". Por su parte, el vicegobernador en funciones en ese momento, Mario Vargas, agregó que "nada ni nadie amilanó a aquellos colonos que llegaron a una tierra desconocida con el convencimiento de encontrar aquí una vida mejor" y que fueron esos pocos galeses quienes hicieron posible "la construcción de una sociedad nueva en tiempos con muchas más complicaciones que las que tenemos hoy".

En definitiva, en los cuatro discursos del 28 de julio de 2011 surgen los mismos valores como valores comunes, como una suerte normatividad derivada de ese "encuentro" entre culturas, la convivencia pacífica, la perseverancia, la tenacidad, el espíritu aventurero, el idealismo, el respeto a la diversidad, la no discriminación, e inclusive la tradición. Esa conjunción normativa aparece celebrada como un ritual identitario de la ciudad, pero también como prerrequisito, como referencia cultural para integrar una "comunidad madrynense" que ha crecido, sobre todo en los últimos cuarenta $a_{n}{ }^{18}{ }^{18}$, en un proceso en el cual se integran una serie de colectivos entre los cuales se encuentra también la narración de las comunidades mapuchetehuelches de la ciudad, muchas veces extranjerizadas por su condición de

\footnotetext{
${ }^{18}$ La población de la ciudad se ha multiplicado por 13 entre 1970 y 2010, según surge de los datos de los Censos nacionales de población de la República Argentina. 
descendientes de mapuches ${ }^{19}$, migrantes de otros lugares de la Argentina y los migrantes de países limítrofes, en especial de la colectividad boliviana, que constituye la colectividad extranjera más numerosa de la ciudad ${ }^{20}$. A su vez, podríamos decir que esta comunización se torna performativa por la naturaleza misma que adquiere el acto, no sólo por existir la "performance" de los representantes de estos dos colectivos primarios $u$ originarios, sino también por la búsqueda de suspensión de los conflictos en los propios discursos, que aún siendo públicos se eligen silenciar.

Por otro lado, en este rito de celebración de un supuesto origen común, hay ciertas cuestiones que aparecen solapadas y que hacen a una mejor comprensión de la importancia del hecho en estos últimos años. En esta perspectiva es que volveremos sobre el concepto de comunidad societal parsoniano en tensión con el multiculturalismo. Mención aparte merece la "carrera del barril" que se realiza al fin del evento, en la cual compiten varias personas, unos por los "colonos" y otros por los "originarios".

\section{4) Multiculturalismo o la expansión de la comunidad societal}

El lonko expresaba que el aniversario de la ciudad los encontraba con una ciudad "hermosa, pujante y de constante crecimiento", teniendo "conciencia y orgullo" de saber que Puerto Madryn está "habitada por hermanos allegados de distinto puntos del país buscando el bienestar

\footnotetext{
${ }^{19}$ Rodolfo Casamiquela sostenía que los mapuches eran oriundos de Chile y conquistaron a los tehuelches (2007), lo que fue tomado como argumento por jueces de la región en litigios por tierras, tal como se refleja en notas periodísticas como la titulada "Dictaminan el procesamiento de miembros de la comunidad originaria Tracaleu por usurpación", publicada el 24/10/2008 en el Diario de Madryn.

${ }^{20}$ Según los cálculos realizados a través de los datos preliminares del último censo nacional, la población de Puerto Madryn sería de aproximadamente 80000 personas al año 2010, de los cuales alrededor de 6000 serían bolivianos. Cabe tener en cuenta que cuando se escribía este artículo aún no eran públicos los datos desagregados de cantidad de habitantes en la ciudad, sino en el Departamento de Biedma, del cual Puerto Madryn es cabecera, como tampoco cuántos de ellos eran extranjeros y, en particular bolivianos, por lo cual el cálculo surge de mantener constantes la proporción de bolivianos en la ciudad del censo anterior respecto del total en la provincia, datos que sí estaban al alcance.
} 
familiar", recordando que "un 28 de julio de 1865, arribaron un puñado de galeses con sus esperanzas a cuestas con la necesidad de creer en un futuro posible en estas tierras".

De la misma forma, la representante de la Asociación Cultural Galesa decía que "había cambiado con los nuevos tiempos el perfil de la ciudad, que había crecido aceleradamente". Afirmaba que recibió a muchos que han dado "nueva forma a este lugar", no ya "la de dos presentes pobladores", sino que "Ios que habitaban y habitan hoy dan forma a los muchos y diversos", "cada uno de los grupos y comunidades que estaban y que se fueron sumando han dado color y definición a esta ciudad". Según ella, Puerto Madryn se caracteriza, como antes, por "la diversidad de culturas que se cruzan y esperamos se integren con el tiempo y forma a un tejido fuerte y respetuoso de cada uno de los hilos de la trama", deseando a su vez que sus nietos y los propios "puedan dentro de mucho tiempo celebrar el encuentro de cultura reconociéndose las diferencias fortaleciéndose con ellas, pero sobre todo buscando y cultivando como se hizo hasta ahora todas aquellas marcas que nos acercan y nos unen como pueblo".

En estos dos discursos había elementos que dejaban entrever cierta mirada de su lugar como colectividades en la construcción de la identidad y la comunidad local, pero también, el reconocimiento del lugar de otros en esa comunidad que mutó, no sólo en términos poblacionales, sino también, consecuentemente, en términos identitarios. Por ello, podemos decir, también, que en el acto, como rito, no sólo se actualizan hechos viejos, tradiciones, sino que se reactualizan los sentidos a través de poner en cuestión lo nuevo, dar lugar o no a otros. Ante esto, nos interesa remarcar que notamos cierta tensión, o forma de tratar la identidad y la diversidad cultural, que puede ser leído o presentado en forma dicotómica, como una comunización cerrada o abierta (Weber, 1984), o, en otros términos como multiculturalismo o como una apertura, o expansión, de la comunidad societal. 
No es casual que la aparición de este festejo con la diversidad de actividades y actores actual, como un acto oficial del municipio, con la actuación del desembarco y del encuentro, así como la rogativa, tenga tan sólo diez años de existencia. Es hacia el 2001 cuando estos tomaron forma, un momento de conflicto social en la Argentina, situación crítica que algunos llegaron a calificar de anomia ${ }^{21}$.

Este surgimiento de los festejos con carácter oficial puede ser pensado como una búsqueda de construir una posible "comunidad", como utopía política, como forma de (re)crear ciertos lazos sociales a través de una recuperación histórica local y regional, aunque no desconectados de ciertas formas nacionales.

Nos interesa plantear que detrás de ese rito, que nosotros calificamos como una relación de comunización, hay una búsqueda de un consenso valorativo de fondo, que por ello tiene efectos en lo que Parsons denominaría comunidad societal. A su vez, éste recoge pedidos de reconocimiento de identidades que antes no tenían el mismo peso en el discurso oficial, en especial en el caso de las comunidades mapuches-tehuelches que estaban en pleno proceso de composición en la ciudad. Este reclamo entra en tensión con otros reclamos, en especial con aquellos que hacen a una mayor igualdad social o a la lucha por los recursos. El multiculturalismo reconoce las diferencias culturales, pero también "reenvía a la imagen de un Estado o de instituciones que aseguran 'desde arriba' el reconocimiento de culturas diferentes, y a la puesta en práctica eventual de medidas sociales para sus miembros". Sin embargo,

"corre siempre el riesgo de fijar las diferencias culturales que reconoce, de prohibir eventuales procesos de descomposición y recomposición. Pero su fuerza radica también en que permite

\footnotetext{
${ }^{21}$ Para comprender el estallido social que se dio en la Argentina en el 2001 recomendamos la lectura del Dossier "A 10 años del 2001: quiebres y continuidades" de Ciencias Sociales, Revista de la Facultad de Ciencias Sociales de la Universidad de Buenos Aires (2011). 
existir a culturas débiles o amenazadas y puede, enseguida, una vez asegurada la sobrevivencia, adentrarse, con olvidos, en relaciones de intercambio" (Wieviorka, 2003: 7).

Además, como afirma Zizek, el respeto "multiculturalista por la especificidad del Otro es precisamente la forma de reafirmar la propia superioridad" (1998: 95), en clara tensión con una apertura de la ciudadanía social, como planteaba Parsons respecto de la ampliación o mayor abstracción de las formas de membresía de la comunidad societal. Tal vez en Parsons había aún esperanza en los beneficios de la modernidad, mientras que los críticos del multiculturalismo ven detrás de una folklorización embelezada de la diferencia intentos de ahogar la diferencia y legitimar la desigualdad.

Si bien hoy aparece ciertamente naturalizado el lugar de las comunidades mapuche-tehuelches en el relato histórico local, debemos tener en cuenta no sólo el carácter performativo del evento, sino también que esto no era así diez años atrás y que hay otros colectivos pujando por un lugar en esa narración. Esto tampoco implica que no existan conflictos alrededor de esta representación, como bien planteamos antes respecto del lugar del mapuche.

Por ello, es importante señalar que no aparecen en un mismo lugar unos y otros en el rito, en este relato, sino que las comunidades mapuchetehuelches aparecen ciertamente subalternizadas ante el colectivo galés, del cual hay una suerte de glorificación como los "héroes de una epopeya", no sólo porque se festeja su llegada (y no la presencia previa de los tehuelches, cuyo carácter pacífico y de ayuda a estos se repite como valor), sino también porque todas las instancias oficiales están cargadas de esta mitología. No sólo se canta el himno galés, sino que el coro municipal canta una canción en galés, no en mapudungun. No resulta casualidad en este sentido que haya un Museo del Desembarco, dedicado sobre todo a los colonos galeses, y un 
CEIC

Museo Provincial del Hombre y del Mar, en el cual, además de lo natural, hay cierta muestra y relatos tehuelches, pero sin lugar a los colonos galeses, hasta mostrando cierta continuidad entre la naturaleza y los habitantes nativos como parte de una historia pasada, ciertamente fijada y folklorizada en relatos y negadora también de la influencia mapuche ${ }^{22}$.

Esto nos devuelve sobre la caracterización de Zizek de la actitud del multiculturalismo que "respeta' la identidad del Otro, concibiendo a éste como una comunidad 'auténtica' cerrada, hacia el multiculturalista mantiene una distancia que se hace posible gracias a su posición universal privilegiada" (1998: 95). Es decir que en el multiculturalismo "la 'tolerancia' liberal excusa al Otro folclórico; privado de su sustancia (como la multiplicidad de 'comidas étnicas' en una megalópolis contemporánea), pero denuncia a cualquier Otro 'real' por su 'fundamentalismo'" (1998: 95).

Queda entonces planteada la cuestión de si este tratamiento es una actitud multicultural ante una demanda de reconocimiento por parte de las colectivos indígenas ( $y$ otros que aparecen como emergentes) o si, en cambio, como reclamaría Parsons para el caso de los afrodescendientes en Estados Unidos, se da una mayor abstracción de la comunidad local para ser más inclusiva, es decir que los límites de la comunidad societal, ese núcleo identitario, valorativo y moral, se vuelven más flexibles para integrar a "otros" que no eran parte, no sólo en términos de la narración identitaria local, sino en cuanto a acceso a ciertos derechos sociales y económicos. Parsons, medio siglo atrás, ya vislumbraba que para poder integrar a colectivos subalternos a la nación en forma real no bastaba con el reconocimiento, sino que era necesario tomar medidas que hicieran a una mayor justicia social, al acceso a derechos sociales y económicos por el alto grado de postergación que en

\footnotetext{
${ }^{22}$ Un trabajo aparte merecería el análisis comparativo del lugar de los distintos colectivos en los museos, monumentos y espacios públicos de la ciudad de Puerto Madryn. Avanza sobre algunas cuestiones en relación con la construcción de una memoria del contacto entre tehuelches y galeses el trabajo de López y Gatica (2008). 
estos campos sufrían. Por ello, proponía, en este mismo sentido, la integración de los que llamó "agrupamientos primordiales" (etnias, parentesco y religioso) en términos de inclusión y no de asimilación, de forma que no perdieran su identidad.

Igualmente, no queremos soslayar que el festejo, en forma de rito repetido, tiene otra cara, una fuerte relación con el problema del orden, en tanto no sólo busca rememorar y, a través de una memoria, construir un futuro, sino también institucionalizar ciertos reclamos de reconocimiento, dado que "el Estado nunca dejó de reivindicar elementos comunitarios como los vinculados con la 'comunidad nacional', a los fines de garantizar la lealtad y la cohesión de los ciudadanos" (de Marinis, 2010c: 67). No es sólo recuperar viejas virtudes en clave moderna.

De todas maneras, tomamos el concepto weberiano de comunización para leer este evento, dado que no es una mera imposición. Comunización "es normalmente por su sentido la contraposición radical de la 'lucha”" (Weber, 1984: 34), por lo que nos permite leer analíticamente esta situación como una relación en la cual hay varios colectivos o grupos que co-construyen, en forma de negociación, o bajo una ficción de paz, la comunidad. Si esto es pensado en términos estratégicos, esa recuperación cultural de la cual hablaba el lonko parecería suplir o, al menos, no poner en cuestión el reclamo por la redistribución económica, pudiendo avalar políticas multiculturales ligadas al neoliberalismo. El ingreso a la nación o, como en este caso, al relato vivo local, tiene su precio en términos de plantear determinadas situaciones como no conflictivas. Eso parece vislumbrarse en ese acto, ficción y ritual. Ahora bien, la realidad actual impone pensar que la justicia no es meramente distribución socioeconómica, sino también reconocimiento, generándose lo que Fraser llamó el "dilema redistribución-reconocimiento" (1997: 26). Pero, resulta importante comprender que estas cuestiones o estrategias que tienden a ser parteaguas hacia adentro de los colectivos, no son simplemente un 
prejuicio entre colectivos extranjeros que "remite directamente al enfrentamiento de clases" (López y Gatica, 2008), sino que son parte de los mismos problemas, dado que, en casos como estos, etnia, o raza, y clase están imbricados, o para tomar palabras de un gran intelectual cuando hablaba del racismo colonial en Argelia, "La causa es consecuencia: se es rico porque se es blanco, se es blanco porque se es rico" (Fanon, 1977: 34). En definitiva, lo que queremos dejar en claro es que más allá que ciertas estrategias se acerquen más o menos al gobierno de turno, compartiendo un escenario como en este caso, o se muestren más o menos combativas e intransigentes negándose a participar del mismo, este análisis no está puesto en declamar la menor o mayor eficacia, sino en revisar las formas en que se festeja, en que se ritualizan determinados hechos, los cuales a largo plazo generan sentidos que se suelen materializar de una u otra forma en los conflictos por recursos, aunque generalmente con relativa autonomía de las intenciones de las actores originales como consecuencias no buscadas de sus actos.

Por último, ya no se trata, en términos de Guha, de "desafiar la univocidad del discurso estatista" (2002: 30), pero sí de dar cuenta de la jerarquización que privilegia un conjunto particular sobre otro, en especial cuando vemos que en el discurso se busca posicionar discursivamente en cierto lugar de igualdad original a dos grupos que fueron castigados y posicionados en formas distintas, incluso recuperados e incorporados en el relato local en momentos y formas diferentes, como es el caso de la colectividad galesa y los pueblos indígenas en la provincia de Chubut y en la ciudad de Puerto Madryn en particular. Sin embargo, cabe la advertencia de de Marinis cuando dice que:

"el Estado no puede renunciar a la retórica de la cohesión y de la integración-inclusión, pero por otro lado juega activamente a la frugalidad y a la economización, apelando a las energías de la 
'sociedad civil'. Algunas comunidades, por su parte, asumen activamente su papel de miembros de la 'sociedad', aunque no de su 'core-group', que se aleja y autonomiza, como barco a la deriva y libre de ataduras que cualquier interdependencia supone" (2010: $67)$.

En este caso, al buscar analizar desde un localismo o particularismo, la vinculación y construcción de la identidad, algunas de estas cuestiones entran en tensión: la relación con lo nacional y lo provincial; con lo oficial; con distintas colectividades que están insertas en el relato identitario local; con otras colectividades que aparecen en búsqueda de su ingreso como un colectivo más; y aparecen campos en los cuales la lucha por los recursos emerge o se pueden rescatar como síntomas de los discursos analizados, siendo que en el rito aparecen silenciados.

En definitiva, en el festejo se busca (re)crear una creencia, un ideal en común, una "comunidad moral" dado que:

"la única hoguera en la que podemos calentarnos moralmente es la que forma la sociedad de nuestros semejantes, y las únicas fuerzas morales con las que podemos sustentar y acrecentar las nuestras son las que otro nos presta. Admitamos incluso que haya realmente seres más o menos análogos a los que nos presentan las mitologías. Para que pudieran ejercer sobre las almas la acción útil que es su razón de ser, sería preciso creer en ellos. Pero las creencias sólo son activas cuando son compartidas" (Durkheim, 1996: 639).

\section{5) CONFLICTOS Y COMUNIDAD LOCAL}

El vicegobernador saliente manifestaba que habían pasado "146 años de aquella epopeya que terminó con cientos de hombres y mujeres desembarcando en estas costas tras un viaje largo y hacia lo desconocido". 
Agregaba que esos hombres y mujeres habían dado "el inicio a esta historia que después otras generaciones continuaron para hacer posible el crecimiento y desarrollo no sólo de Puerto Madryn sino también de gran parte de nuestra provincia". Sostenía, así, que los habitantes de Chubut tenían "la obligación moral de continuar esa colonización gigantesca refundando la esperanza y haciendo posible un nuevo sueño".

Wieviorka habla de "identidades primarias" (2003) que resisten a la modernidad, aún cuando uno pueda diferir y marcar que buena parte de ellas se constituyeron en la modernidad como tales. Claro está que detrás de cierta homogeneización de pueblos detrás de motes como "pueblos originarios", más que mitos ${ }^{23}$, hay una multiplicidad de conflictos, proyectos, de historias de pueblos distintos, de resistencia, negociación, incorporación, transformación, de repliegue y despliegue. Por ello dice que "afirmarse es molestar a los otros, es reclamar un reconocimiento, es decir que su identidad colectiva amerita un lugar, que es una infamia o una barbarie o la carencia debida a una inferioridad" (Wieviorka, 2003: 4).

Sin embargo, lo que vemos en este caso es una búsqueda de inclusión y ser incluidos como forma de integrar la "comunidad local madrynense". Estos ritos laicos, "episodios de calentamiento de lazo social", no son meros actos, sino que tienen efectos en las representaciones colectivas y, en consecuencia, en las formas en las cuales se habilita a dar tratamiento a ciertos colectivos.

Durkheim nos advierte que "la conciencia colectiva es algo más que un simple epifenómeno de su base morfológica, lo mismo que la conciencia individual es diferente de una simple inflorescencia del sistema nervioso" (1996: 637), no sólo como una forma de diferenciarse de los seguidores de

\footnotetext{
${ }^{23}$ En este sentido, resulta interesante la discusión en torno a si se puede hablar de genocidio o no en el $\mathrm{N}^{\circ} 2$ de la Revista Corpus y las referencias a la nota de Luis Alberto Romero, titulada "El mito de los pueblos originarios", publicada en el Diario Perfil el 20 de noviembre de 2011, en Vezub (2011). 
CEIC

Marx más economicistas, sino también porque en su pensamiento teórico y político concibe la transformación moral de la sociedad como forma de alcanzar una sociedad más cohesionada. No es casual que las autoridades municipales, en un momento de crisis no sólo económica, sino de representación, y podríamos agregar de valores, como fue el 2001 en la Argentina, tomaran ciertos relatos que permitían una lectura pacífica de la historia local e intentaran darle un carácter más oficial, como un festejo ampliado de la propia comunidad. No es que antes no se festejara ese día, sino que no tenía la pluralidad de participaciones que sí tiene al día de hoy. Esto no implica que veamos esto como algo construido en forma completamente mentada, "desde arriba", sino que debemos comprender que no es casual el momento en que determinadas miradas se oficializan al punto de institucionalizarse ${ }^{24}$.

Por último, nos interesa retomar cuáles eran las fisuras, los intersticios de los relatos actuados en el rito y los emergentes que daban cuenta, no sólo en forma sintomática sino también explícita, de determinados conflictos sin resolver en la ciudad.

Cabe tener en cuenta, en primer lugar, que así como la (re)creación del desembarco y del "encuentro de dos culturas" mostraba aquello que se leyó en los discursos, la convivencia pacífica, el respeto y la perseverancia como valores heroicos de los antepasados fundadores y habitantes de la ciudad, estos discursos en ningún momento mostraron enfrentamientos, tan sólo dejaban entrever conflictos de los cuales no se habló en forma explícita.

En este sentido, el lonko decía que todos los años le pedía los dirigentes y gobernantes por la preservación de los bienes naturales "la

\footnotetext{
${ }^{24}$ Cabe tener en cuenta, en este sentido, el lugar reconocido en la reforma de la Constitución de 1994 a los pueblos indígenas argentinos en el Artículo 75, inciso 17 y la aparición pública cada vez más notoria en varios conflictos de distintos colectivos indígenas. Un ejemplo en la Provincia del Chubut ha sido la situación de la recuperación de Santa Rosa Leleque, en tierras que había adquirido la firma Benetton, y la formación de la organización de comunidades mapuche-tehuelche " 11 de octubre".
} 
preservación del medio ambiente, factores fundamentales para nuestras vidas". Explicitaba que "debemos pensar en intereses colectivos y no intereses personales" y postulaba como ejemplo lo hecho por los galeses y tehuelches que había trabajado la tierra sin afectar lo fundamental para la vida, "así se parió el encuentro entre dos culturas un lindo ejemplo de imitar con valores esenciales para una convivencia en armonía, para convivencia en paz preservando, por sobre todas las cosas, el espacio que habitábamos".

Si bien no hay mención explícita, el lonko cerró pidiendo por un tema conflictivo a nivel provincial porque, más allá de la protección del ambiente de la ciudad, existe un conflicto a nivel provincial por la explotación de la minería a cielo abierto, prohibida por la Ley provincial 5001 de 2003 luego del "No a la Mina" en Esquel, pero actualmente en discusión por el proyecto de yacimiento minero en el centro norte de la provincia, en una zona pobre, árida y con pocos habitantes, y con importante presencia de comunidades indígenas. Sin embargo, por la naturaleza no confrontativa del acto, el intendente, luego de los dichos del lonko aseveró que durante su gestión avanzaron "hacia el vertido cero de afluentes al Golfo Nuevo", pudiendo atribuir a su gestión municipal un fuerte y adecuado tratamiento del medio.

Por otro lado, el propio intendente decía que la historia se escribía "como protagonista", que la historia de galeses y tehuelches "que es nuestra historia", "se fue enriqueciendo, con historias de vascos, italianos, sirios libaneses, gallegos, portugueses, entre otros, que también eligieron a Puerto Madryn como su ciudad". De esta manera, le daba ingreso a la narración de la historia de la ciudad, en el mismo sentido que en el relato nacional, a aquellos llegados en las migraciones transoceánicas propias de fines del siglo XIX y principios del $\mathrm{XX}$, dejando por fuera a otros colectivos presentes en el acto, pero no mencionados en ninguno de los discursos.

Aquí los inmigrantes limítrofes no parecerían ser parte de la identidad de la ciudad, en especial los bolivianos que son hoy la colectividad extranjera 
más numerosa de la ciudad, aun cuando, como en los últimos años ${ }^{25}$, acompañaron el acto con la presencia de su asociación de residentes, mostrando su búsqueda de integrar el relato identitario local. Son ellos hoy los que más sufren la discriminación siendo objetivo de buena parte de los prejuicios que circulan en la ciudad.

En este sentido, y yendo al último de los conflictos locales que se pudo entrever a través del acto, resulta bastante particular la aparición de la única presencia disonante en el transcurso del mismo, las banderas argentinas y las pancartas de protesta que llevaban personas de asentamientos y/o con conflictos de vivienda en la ciudad, que le reclamaban al intendente Eliceche. Es para remarcar que el conflicto habitacional es el único que aparece en forma explícita en el acto. Las personas que fueron en protesta estaban del otro lado de la calle de donde se encontraba el escenario y tenían pancartas que decían "estafados presentes", "Basta de promesas falsas", "Basta de corrupción", "Pueblo y gente unida por una vivienda digna", "tenemos derecho a una vivienda digna". A su vez, su intervención fue hacer ruido en los momentos en los cuales se presentaron tanto el intendente, objetivo central del bullicio que generaban, como el vicegobernador. También, en aquellos momentos en los cuales estos dos hablaron de la vivienda, del hábitat o de la posibilidad de cambio. Asimismo, si bien una parte de los ocupantes de tierras que hay en la ciudad son bolivianos, no había presencia de ellos y los que estaban se manifestaban con banderas argentinas, como si en el mismo acto de protesta estuvieran diferenciándose de aquellos que no son argentinos y que están en la misma situación.

\footnotetext{
${ }^{25}$ Queda pendiente para otro trabajo analizar el cambio de postura de la Asociación de Residentes Bolivianos Wiñay que, según nos relataron, en los últimos cuatro o cinco años dejó de realizar actividades sólo en los barrios con presencia mayoritaria de población de origen boliviano para comenzar a participar más en distintos festejos y actividades públicas. 


\section{6) CONCLUSIONES: ENTRE LA IDENTIDAD LOCAL Y EL CONFLICTO SOCIAL}

En este texto nos interesó presentar una entrada posible a las formas que adquiere la segregación en la ciudad de Puerto Madryn. En este caso, la identidad local sirvió de llave de ingreso, articulando un evento, como un rito o festejo identitario, con las formas en que se jerarquizan y subalternizan colectivos sociales. En el sentido planteado por Lukes, en los rituales no todo es reproducción, sino que se movilizan conflictos e intereses (1975). Los desarrollos teóricos de autores clásicos como Weber, Durkheim y Parsons, nos permitieron alumbrar con ojos comunitarios la tan buscada construcción de identidad y comunidad local en donde llevamos adelante nuestro trabajo de campo ${ }^{26}$. Queda claro de las conceptualizaciones que desarrollamos que estos comprendían la necesidad de valores y creencias que otorgaran sentidos a la desencantada vida moderna. No por ser modernistas dejaban de ser ciertamente críticos de la realidad en la cual vivían.

A través de esta lente es que intentamos vislumbrar estas narraciones, las cuales adquieren cierto carácter performativo en el tratamiento de la conflictividad social local. En estos ritos aparecen suspendidos o silenciados ciertos conflictos, otros hacen síntoma, mientras que los más urgentes emergen con independencia del relato mismo aunque en sintonía con la representación colectiva que conecta Puerto Madryn con la nación argentina. La cuestión de la comunidad, tan cara como imagen identitaria en ciudades de tan vertiginoso crecimiento como este, mezcla temporalidades biográficas e históricas llegando en ciertas circunstancias a definir el acceso a derechos (o la falta del mismo).

Hoy podemos decir que la construcción de la comunidad societal madrynense, o las imágenes de comunidad, que pudimos retratar a través del

\footnotetext{
${ }^{26}$ Otra arista interesante para pensar el concepto de comunidad, que vemos en nuestro trabajo de campo en la ciudad, es la repetición discursiva del enfoque comunitario como "el" enfoque de trabajo de diversas instituciones públicas que trabajan en cuestiones y formas distintas. 
festejo del 28 de julio que relatamos reconoce a los pueblos originarios como habitantes nativos originarios. A su vez, los subalterniza en relación con otros colectivos como los colonos galeses o los migrantes transoceánicos, pero los integra al relato identitario local, redefiniendo su membresía anterior. No sucede lo mismo con los inmigrantes limítrofes, colocando a estos últimos en un nivel de subalternidad aún mayor, lo que no sólo se trasluce a través de la ausencia en los relatos con relación a la presencia en el acto, sino también en la forma en que aparece el conflicto más urgente de la ciudad, el habitacional.

En este sentido, podemos decir que, aunque se pueda ver a la participación de la comunidad mapuche-tehuelche en este relato como legitimador de la narración de una colonización benevolente galesa, también debemos tener en cuenta cuáles son los sentidos y reconocimientos que ese relato habilita para una mayor integración en términos de estrategia política de negociación, encuentro o comunización.

\section{7) Bibliografía}

Alexander, J., 2005, "Contradictions in the Societal Community: The Promise and Disappointment of Parsons' Concept", After Parsons: A Theory of Social Action for the Twenty First Century, Fox, R. C, V. Lidz y J. Harold, Russell Sage Foundation, New York, pags. 93-110.

Baeza, B., E. Crespo y G. Carrizo, 2007, Comodoro Rivadavia a través del Siglo XX. Nuevas miradas, nuevos actores, nuevas problemáticas, Editorial Municipal de Comodoro Rivadavia.

Casamiquela, R., 2007, Rodolfo Casamiquela racista antimapuche: o la verdadera antigüedad de los mapuches en la Argentina, Biblioteca Popular Agustín Álvarez, Trelew.

de Marinis, P., 2005, "16 comentarios sobre la(s) sociología(s) y la(s) comunidad(es)", Papeles del CEIC, № 15, CEIC, Universidad del País Vasco, España, enero, http://www.identidadcolectiva.es/pdf/15.pdf 
de Marinis, P., 2010a, "La comunidad según Max Weber: desde el tipo ideal de la Vergemeinschaftung hasta la comunidad de los combatientes", Papeles del CEIC, CEIC, Universidad del País Vasco, España, marzo, http://www.identidadcolectiva.es/pdf/58.pdf

de Marinis, P., 2010b, "Sociología clásica y comunidad: entre la nostalgia y la utopía (un recorrido por algunos textos de Ferdinand Tönnies)", en de Marinis, P.; Gatti, G.; Irazuzta, I. (eds.), La comunidad como pretexto. En torno al (re)surgimiento de las solidaridades comunitarias. Editorial Anthropos y Universidad Autónoma Metropolitana-Iztapalapa, Barcelona y México DF, pags. 347-382.

de Marinis, P., 2010c, "Estado y comunidad, de los clásicos a Parsons (y más allá)", Propuesta Educativa, Año 19 №33, junio.

Durkheim, E., 1996, Las formas elementales de la vida religiosa. Alianza Editorial, Madrid.

Fanon, F., 1977, Los condenados de la tierra, Fondo de Cultura Económica, México.

Fraser, N., 1997, lustitia interrupta. Reflexiones críticas desde la posición postsocialista, Colombia, Siglo del Hombre editores, Universidad de Los Andes. Cáp.1.

Golluscio, L., 2006, "Lengua-Cultura-Identidad. El discurso ritual mapuche. Un universo de autonomía cultural", 20 años de Sociedad y Religión. Aportes para un estudio de la religión en la Argentina, CEIL-PIETTE, Buenos Aires, pags. 29-45.

Grondona, A., 2010, "La sociología de Emile Durkheim. ¿Una definición 'comunitarista' de lo social?", Papeles del CEIC, CEIC, Universidad del País Vasco, España, marzo, http://www.identidadcolectiva.es/pdf/55.pdf

Guha, R., 2002, Las voces de la historia y otros estudios subalternos, Ed. Critica, , Barcelona.

Jones, N., 2004, "Vinieron para quedarse. Breve historia de los galeses en Chubut", Cuadernos de Historia Patagónica, №1, Centro de Estudios Históricos y Sociales de Puerto Madryn, Puerto Madryn. 
Kaminker, S., 2011, "La dimensión racial en el análisis de la segregación residencial urbana en Puerto Madryn, Chubut". Papeles de trabajo n.22, dic. 2011- Cent. Estud. Interdiscip. Etnolingüíst. Antropol. Sociocult., Rosario.

Lopez, S. y M. Gatica, 2008, "La construcción de una memoria, a propósito del contacto entre galeses y tehuelches", 3er Foro Internacional sobre los galeses en la Patagonia, Fundación Ameghino, Centro de Estudios Históricos y Sociales de Puerto Madryn, Asociación Punta Cuevas, Trelew.

Lukes, S., 1975, "Political Ritual and Social Integration", Sociology 1975, 9, May, SAGE, pags. 289-308, http://soc.sagepub.com/content/9/2/289.

Nisbet, R., 1996, “Comunidad”, en La formación del pensamiento sociológico 1. Buenos Aires, Amorrortu, pp. 71-145.

Parsons, T., 2012 [1965], “¿Ciudadanía plena para el Norteamericano Negro? Un problema sociológico", Entramados y perspectivas. Revista de la Carrera de Sociología, Vol. 2, № 2 enero - junio 2012, Universidad de Buenos Aires, pags. 235-278.

Ramos Torre, R., 2010, "La comunidad moral en la obra de Émile Durkheim", en de Marinis, P.; Gatti, G.; Irazuzta, I. (eds.), La comunidad como pretexto. En torno al (re)surgimiento de las solidaridades comunitarias. Editorial Anthropos y Universidad Autónoma Metropolitana-Iztapalapa, Barcelona y México DF, pags.383-412.

Ribes Leiva, A., 2010, "Durkheim contra Durkheim: Los límites de la lógica secuencial totalidad-fragmentación", Nómadas. Revista Crítica de Ciencias Sociales $\quad$ S Jurídicas, http://www.ucm.es/info/nomadas/28/albertojribes.pdf.

Sanabra, C., 2004, "Desarrollo urbano de Puerto Madryn. Desde sus orígenes hasta 1970", Cuadernos de Historia Patagónica, №1, Centro de Estudios Históricos y Sociales de Puerto Madryn, Puerto Madryn.

Torterola, E., 2010, "Racionalización y comunización en la esfera económica. Los matices del individualismo en la teoría de la modernidad 
weberiana", Papeles del CEIC CEIC, Universidad del País Vasco, España, marzo, http://www.identidadcolectiva.es/pdf/56.pdf

Vezub, J., 2005, "Redes comerciales del País de las Manzanas. A propósito del pensamiento estructural de Guillermo Madrazo", Revista Andes, № 16, CEPIHA, Facultad de Humanidades, Universidad Nacional de Salta.

Vezub, J., 2011, "1879 - 1979: genocidio indígena, historiografía y dictadura", en Corpus. Archivos virtuales de la alteridad americana, $\mathrm{N}^{\circ} 2$ Vol. I, Mendoza.

Weber, M., 1984, Economía y Sociedad. Esbozo de Sociología Comprensiva. Fondo de Cultura Económica, México.

Wiewiórka, M., 2003, "Diferencias culturales, racismo y democracia", en Mato D.: Políticas de identidades y diferencias sociales en tiempos de globalización, FACES - UCV, Caracas.

Williams, A., 2007, "Hacia una historia de la historiografía de la colonia galesa" en $X I^{\circ}$ Jornadas Interescuelas, Departamentos de Historia, Universidad Nacional de Tucumán.

Zizek, S., 1998, "Multiculturalismo, o la lógica del capitalismo multinacional", en Jameson, F. y Zizek, S. Estudios culturales. Reflexiones sobre el multiculturalismo, Paidos, Buenos Aires.

2011, "A 10 años del 2001: quiebres y continuidades", Ciencias Sociales, Revista de la Facultad de Ciencias Sociales de la Universidad de Buenos Aires, $\mathrm{N}^{\circ}$ 79, Diciembre, http://www.sociales.uba.ar/wpcontent/uploads/79 doble-pagina.pdf. 
Protocolo para citar este texto: Kaminker, Sergio Andrés, 2014, "Construcción de Comunidad: un 28 de julio en la ciudad de Puerto Madryn", en Papeles del CEIC, vol. 2014/1, n 105, CEIC (Centro de Estudios sobre la Identidad Colectiva), Universidad del País Vasco, http://www.identidadcolectiva.es/pdf/105.pdf

Fecha de recepción del texto: Mayo de 2012

Fecha de evaluación del texto: Agosto de 2012

Fecha de publicación del texto: Marzo de 2014 